\title{
Accidental exposure to electromagnetic fields from the radar of a naval ship: a descriptive study
}

\author{
Bente E. Moen ${ }^{1,2}$, Ole Jacob Møllerløkken ${ }^{1}$, Nils Bull ${ }^{3}$, Gunnhild Oftedal ${ }^{4}$, Kjell Hansson Mild $^{5}$ \\ ${ }^{1}$ Department of Global Public Health and Primary Care, University of Bergen, Norway \\ ${ }^{2}$ Department of Occupational Medicine, Haukeland University Hospital, Norway \\ ${ }^{3}$ Department of Ophthalmology, Haukeland University Hospital, Bergen, Norway \\ ${ }^{4}$ Sør-Trøndelag University College (HiST), Trondheim, Norway \\ ${ }^{5}$ Department of Radiation Sciences, Umeå University, Umeå, Sweden
}

\begin{abstract}
Part of a crew on a Norwegian naval ship was exposed to the radar waves for approximately 7 min from an American destroyer during an incident at sea in August 2012. Information about the exposure was not given by the navy. This is a description of what happened with the crew on board after this event. 14 persons had been on the ship bridge or outside on the deck during the exposure and the rest of the crew had been inside the ship. 27 persons were examined at a hospital 6-8 months after the event, as they had developed a large number of symptoms from different organ systems. They were very worried about all types of possible adverse health effects due to the incident. All were examined by an occupational physician and an ophthalmologist, by an interview, clinical examinations and blood tests at the hospital. The interview of the personnel revealed that they had not experienced any major heating during the episode. Their symptoms developed days or weeks after the radar exposure. They had no objective signs of adverse health effects at the examination related to the incident. Long-term health effect from the exposure is highly unlikely. The development of different symptoms after the incident was probably due to the fear of possible health consequences. Better routines for such incidents at sea should be developed to avoid this type of anxiety.
\end{abstract}

(Int Marit Health 2013; 64, 4: 177-182)

Key words: electronic interference, microwaves, navy, warmth feeling

\section{INTRODUCTION}

Part of the crew on a Norwegian coastal guard ship was accidently exposed to electromagnetic fields (EMF) from the radar on an American destroyer during an exercise in the Barents Sea on August $24^{\text {th }}, 2012$. The American ship passed with a distance of about $70-100 \mathrm{~m}$ from the Norwegian ship, and several of the crew was standing outside on the deck to watch the event. By mistake, the radar on the American ship was not turned off during the event. The time for the ships to pass each other, and thus the assumed exposure period, was about $7 \mathrm{~min}$. The radiation was detected as electronic interference; instruments on the Norwegian ship were disturbed, e.g. monitors and navigation instruments on the bridge stopped working and fire alarms were initiated on board. Some of the crew on the bridge of the Norwegian ship realised that the radar on the U.S. ship was in function and contacted the American ship. The radar was then switched off. About half a year later several members of the crew were referred to the Hospital Department of Occupational Medicine in Bergen, Norway, with different health problems. They were interviewed and examined, and the results are summarised in this article.

Radars have been used extensively in military defense for many years and are also useful for other purposes, where localisation of objects is needed. Radar is an acronym for 'radio detection and ranging'. Conventional radar emits electromagnetic fields in the microwave range in form of powerful, but very short pulses. From objects like, for instance, moun-

Bente E. Moen, Occupational and environmental medicine, Department of Global Public Health and Primary Care, Kalfarveien 31, N-5020 Bergen, Norway, tel: +47 55586112, telefax: +47 55586105, e-mail: bente.moen@isf.uib.no 
tains, ships and aircrafts, the reflection of radio wave pulses can be detected with a radio receiver. The time difference between the transmitted pulse and the echo can be used to determine the distance and movement of the reflecting object.

The relationship between exposure to radio frequency (RF) EMF from radars and adverse health effects has been discussed as long as the radar has been in use. High exposure levels can have serious negative health effects and can even be deadly. A few such cases have been reported in literature [1-4]. In these cases the fields had caused immediate damage to internal organs, as the persons had been present very close to the transmitting antenna. Due to this possible hazard from RF EMFs, exposure limits have been developed to control the work and health situation in locations where radars are used. If an 'over-exposure' occurs from a radar beam, this can provide a warm feeling on the exposed part of the body. Warm feeling passes to pain if the exposure is strong enough - and this can make the exposed person move out of the beams. High exposure can cause immediate nausea and vomiting. Headache and tiredness are described as immediate effects as well, but it is also mentioned in the literature that these symptoms might not be caused by the direct effect of the fields $[5,6]$. These symptoms might be secondary, due to developed anxiety among persons involved in the 'over-exposure'. Heating above $43^{\circ} \mathrm{C}$ may cause coagulation of the proteins and lead to cell damage, for example burns of the skin or changes of the lens in the eyes [7]. Eyes are very vulnerable, because they do not have an adequate cooling from blood circulation. Without the presence of visible burns or clear heat sensation, it is considered unlikely that the radiation may cause health effects [8].

The past years several studies of long-term effects of RF EMF and health have been performed. Several summaries of the present knowledge in the area have been presented [9-11], including specific studies regarding radar exposure [12]. The conclusion from these reports is that there are no long-term health effects caused by exposure to low levels of RF EMF, without heating effects, and this is also the situation for similar exposure to fields emitted from radar.

The hospital department found the situation worrying and contacted the navy when 14 persons had been referred. The hospital personnel was informed that the navy could not handle the situation themselves, and wanted help. The hospital department quickly planned a project and the navy was given the opportunity to refer more patients, as there were more personnel with similar problems among the crew members on the affected ship.

The purpose of this article is to describe the experience of accidental exposure and the symptoms developed among the crew members. We would also like to discuss the exposure and how such situations should be handled. We hope this can be helpful in future incidents of similar type.

\section{MATERIALS AND METHODS}

At the event, there were 66 persons on board the Norwegian ship. All persons who had been on the bridge and others who had been present outside on the deck of the ship during the radar exposure episode (14 persons) were referred to the hospital by the navy and asked to join this project. In addition, others on board who were concerned about adverse health effects were included. In total, 29 persons were referred in the period from November 2012 to January 2013.

All the persons were interviewed by an occupational physician about the event, where they had been, what they had experienced, and about the presence of symptoms during the episode, as well as later. Symptoms at the time of examination were obtained by a questionnaire asking about the presence of 29 different subjective health complaints in the past 30 days, rated on a scale from 0 to $3[13,14]$. The health complaints were summarised into 5 subscales: musculoskeletal (8 items), pseudoneurological (7 items), gastrointestinal ( 7 items), allergic (5 items) and flu-like ( 2 items).

In addition, information about sex, age, years of experience on board and previous diseases was obtained. Each person was examined by a clinical examination of blood pressure, auscultation of the chest, observation of the skin, palpation of the abdomen, neurological status and mini mental state [15]. An eye examination was performed by an ophthalmologist, including best corrected visual acuity and monitoring eye pressure. The tear film break-up time was measured and if it was pathological, a Schirmer test was performed. The pupil was dilated with Tropicamide and the anterior and posterior part of the eye examined using a slit lamp, with particular focus on the cornea and lens. A blood sample was taken and analysed for haemoglobin level, blood count, red cell volume, liver function (alanine transaminase), renal function (urea, creatinine), thyroid hormones (thyrotropin, thyroxine and triiodothyronine) and immunoglobulines (Immunoglobulines A, E, G and M). Among males luteinizing hormone, follicle-stimulating hormone, testosterone, sex hormone-binding globuline, prolactin and oestradiol were analysed as well. As some of the crew members had been examined by different physicians both inside and outside the navy after the radar exposure event but before the examination in this project, these were contacted to obtain their medical reports.

The Royal Norwegian Navy was contacted several times about the event for more exposure information. They provided an internal commission report on the event and some short notes from physicians who had been on board the ship at the event and in the period after, but claimed that no other information did exist and that they could not ask for it due to military secrecy among the nations. Therefore, other sources for exposure information were sought: available literature and the Internet. 
Ethical clearance was obtained from the Regional Committee for Medical and Health Research Ethics West, and all participants gave their written consent.

\section{RESULTS}

\section{EXPOSURE ASSESSMENT}

No one in the navy had any information on the exposure from the radar, they only informed about the name of the radar. However, we have deduced the following information: the radar was a SPY-1D (V), an S-band radar using frequencies 3-4 GHz, wavelength 7.5-10 cm [16]. The peak output power of this radar is $6 \mathrm{MW}$ and the average power is $58 \mathrm{~kW}$, which gives a duty cycle of about $1 / 100$. The antenna gain can be calculated from the handbook formula $G=27000$ / /(square of lobe width) [17]. With the lobe width given as $1.7^{\circ}$, the gain will be 9300 . With an estimated distance between the ships of $90 \mathrm{~m}, \mathrm{r}$, we will have an estimated peak power density (S) of $550 \mathrm{~kW} / \mathrm{m}^{2}$, according to the formula: $\mathrm{S}=\mathrm{G} \times \mathrm{P} / 4 \pi \mathrm{r}^{2}$, where $\mathrm{P}$ is the peak output power. Calculating the peak electric $(E)$ field in the pulse from the formula $\mathrm{S}=\mathrm{E}^{2} / 377$, this will be about $15 \mathrm{kV} / \mathrm{m}$. Since the SPY radar has a pencil beam form and has a random search pattern, it is not possible to calculate the exact exposure of the personnel on board the Norwegian ship. If the beam was located at the same spot for some seconds, the mean power density then would be of the order of $5.5 \mathrm{~kW} / \mathrm{m}^{2}$.

The rate at which the energy is absorbed by the body when exposed to RF EMF can be measured by the specific absorption rate (SAR). Whole-body exposure at 3-4 GHz gives a SAR $=0.02 \mathrm{~W} / \mathrm{kg}$ per incoming $1 \mathrm{~W} / \mathrm{m}^{2}$. For an average of $1 \mathrm{~s}$, with the beam located at the same spot, this will give an exposure of $110 \mathrm{~W} / \mathrm{kg}$. The specific absorption $(\mathrm{SA})$ during 1 pulse can be calculated from $\mathrm{SA}=\mathrm{S} \times 0.02$ $(\mathrm{W} / \mathrm{kg}) /\left(\mathrm{W} / \mathrm{m}^{2}\right) \times \mathrm{t}$, where $\mathrm{t}$ is the pulse length. From data on the net, the pulse length can be up to $50 \mu \mathrm{s}$ [17], and this would then give $\mathrm{SA}=0.55 \mathrm{~J} / \mathrm{kg}$.

\section{PARTICIPANTS}

Twenty-seven persons participated in the study; only 2 referred persons did not come to the hospital. 23 men and 4 women, aged $20-46$ years were examined in the period from January to April 2013. They had on average been employed in the Coast Guard Ship for 3 years, ranging from 1 to 19 years. None of them had been diagnosed with any previous chronic disease or used any medication (except from birth control pills among females).

\section{HEALTH PROBLEMS AT THE DAY OF THE ACCIDENTAL EXPOSURE, AUGUST 24 ${ }^{\text {TH }}$}

Five of the crew on the bridge and 2 of the crew standing outside on the deck on the same side of the ship where the
American ship passed, felt a slight sensation of warmth on the face during the radar incident. This sensation lasted for a very short period, not more than seconds or minutes. Two of those on the bridge also felt a mild heat sensation on the left arm; this side of their body was turned towards the passing ship. One of the persons on the bridge also described pain in the jaw. The persons on the bridge could not remember for how long these sensations lasted.

Two of the crew were sitting inside the ship when the fire alarm went off and ran out on the deck to perform their duties during the alarms. They described a slight warm sensation on the face and on their arms. None of the personnel observed any visible burns or affections of their skin - not on themselves and not on any other person. None of the crew had symptoms from the eyes that day, including pain of the eyes, photophobia or other form of irritation from the eyes.

During the incident a physician was on board, and stayed there for 4 days. He was in the galley inside the ship at the time of the accidental exposure. He noticed no health problems to himself. He observed no signs of affection of the skin or eyes of anyone on board this day. No burns or visible health damage were observed or reported while he was on board.

\section{HEALTH PROBLEMS SOME DAYS AFTER THE EVENT}

The incident happened at the end of the maritime exercise, on Friday. The Norwegian ship continued sailing, as planned, to a harbor in Russia. Here the crew had the weekend off, with sightseeing, parties and relaxation. Two days later the ship sailed to the small town Kirkenes in Norway, where some of the crew (including the physician) left the ship, and then the ship continued sailing. They were to sail in the ocean and perform their normal work.

However, the ship journey was interrupted, as the crew started to report many different health problems. Later it was revealed that the crew had been writing a symptom diary twice a day. It is a bit uncertain when they started this and also how long they continued. The ship went to Troms $\varnothing$ harbor and some of the employees were examined at the emergency department there on September $4^{\text {th }}$. The hospital reports describe no signs of disease related to radiation, no signs of burns, cataracts in the eyes, anaemia, nor dysfunction of testes. A meeting was held with the crew and commanders in the navy, including persons responsible for occupational health and radiation. The crew was informed about the 'over-exposure' event. It was confirmed that the fields from the American radar had caused the electronic disturbances on board. Regarding the information on possible adverse health effects, it is not clear what kind of information the crew received. Some of them told that they became more anxious after this meeting. Some of the crew mentioned that the physicians they had contact with told them that they knew nothing about radar and health effects. 
The crew asked to have a physician on board when sailing from Troms $\emptyset$, and this was organised. The physician performed an interview of the crew on board, totalling 46 persons. At this time the crew reported problems with headache (43\%), fatigue (26\%), sweating (20\%), pain/burning sensation on the skin (15\%), and impaired/disturbed vision (7\%). Furthermore, they reported strange feelings in the ear, hearing loss, pain in testicles, nose-bleeding, nausea, and chest discomfort. The onset of symptoms showed considerable variation. One week later the physician wrote in a note that: 'At the follow-up a week after the original survey, only 1 individual has health problems. The remaining crew has no problems or complaints.'

However, the crew had several questions regarding the event even after this time. They all described that they talked a lot about the radar incident on board, and they wanted to know more about the exposure and the possible health effects. They all claimed that the information they were given was scarce, and that they became worried. Some of them described that they thought their symptoms developed because they discussed different possible diseases that could be caused by radiation, for instance cancer of the brain and infertility. The weeks passed and members of the crew still complained about the occurrence of different symptoms. In a note from November, more than 2 months after the incident, a marine medical officer reported to have a follow-up examination of 33 persons from the ship. At this time the crew complained about focusing problems, photophobia, headache of various kinds, fatigue and lack of energy. The physician described that they were anxious. Several of the crew were on sick leave and could not work. This was the situation when the crew was referred for examination to the hospital in Bergen at the end of November 2012.

\section{COMPLAINTS IN 2013}

The prevalence of subjective health complaints 30 days preceding the examination was quite low among the examined crew (Table 1). The results are here compared with similar results from a study on a normal population on shore in Norway, both men and women in a similar age group [18]. The prevalence of complaints was low for all the subscales.

At the interview half of the crew expressed they were afraid that their DNA had been damaged, that they have become infertile and also they worried about higher risk of developing cancer or other diseases later in life due to the radar incident. All mentioned that they want more information about the radar exposure levels, and that they are very worried, since minor information had been given to them about this.

\section{EXAMINATIONS}

All participants had normal blood pressure, normal findings by auscultation of the chest, palpation of the abdomen, as well as normal neurological status. Twenty of the partici-
Table 1. Scores of subjective health complaints among crew members on a naval ship 5-8 months after experiencing a radar 'over-exposure' incident, compared to the results from a population study [*18]

\begin{tabular}{lll}
\hline $\begin{array}{l}\text { Subjective } \\
\text { complaints }\end{array}$ & $\begin{array}{l}\text { Crew }(\mathbf{n}=\mathbf{2 7}) \\
\text { Median score }\end{array}$ & $\begin{array}{l}\text { Population sample } \\
<\mathbf{4 0} \text { years }(\mathbf{n}=\mathbf{8 1}) * \\
\text { Median score } \\
\text { men/women }\end{array}$ \\
\hline Musculoskeletal & 0.6 & $2.1 / 2.2$ \\
Pseudoneurological & 0.5 & $1.2 / 2.2$ \\
Gastrointestinal & 0.1 & $0 / 2.1$ \\
Allergic & 0 & $0 / 1.0$ \\
Flu-like & 0 & $1.1 / 1.0$
\end{tabular}

pants had a score of mini mental state of 30 , which is the best possible score; the other 7 had a score of 27-29. One person had an irregular pulse, but it was normal at a control few weeks later. Two persons had a rash of the skin due to newly started infections, no other skin abnormalities were found.

The eye examination revealed no pathology of the lenses in the eyes of any of the participants. Seven of the crew complained to have 'dry eyes' at the examination, and the tear production was found to be low among 3 of them. These problems occurred among the crew who had been inside the ship when the exposure took place, and who had entered the deck in the last part of the exposure. Seven cases of myopia, 3 cases of hypermetropia and 2 cases of keratoconus were found by the eye examination. All blood analyses were normal.

Due to serious worries, 3 persons were examined by magnetic resonance imaging of the brain and 1 person had a semen examination. The results from these examinations were normal.

\section{DISCUSSION}

There is no doubt that the Norwegian naval ship was exposed to RF EMF from the radar of the American ship passing by. The exposure is not known in detail, but instruments on board were affected. In our exposure evaluation, we calculated the peak pulse of the E-field to be $15 \mathrm{kV} / \mathrm{m}$. This exposure will be able to permanently damage unprotected electronics. However, interference occurs at much lower levels.

A slight feeling of warmth on the skin of face and/or arms was described by 9 persons from the crew. Our calculations of possible average exposure levels for a second or so $\left(5.5 \mathrm{~kW} / \mathrm{m}^{2}\right.$, which is equivalent to the SAR of $\left.100 \mathrm{~W} / \mathrm{kg}\right)$ indicate the warmth may have been caused by the radar exposure. In experimental studies it has been shown that the temperature threshold for detection of warmth sensation from microwaves exposing a small skin area of a person for 3 to $10 \mathrm{~s}$ is of the order of 0.05 to $0.08^{\circ} \mathrm{C}$ [19]. In human volunteers under- 
going partial-body RF exposure, the warmth sensation can be detected immediately by applying continuous exposure with power density of $270 \mathrm{~W} / \mathrm{m}^{2}$ at $2450 \mathrm{MHz}$, giving rise to a spatial peak SAR of $6.6 \mathrm{~W} / \mathrm{kg}$. On the other hand, the exposure cannot have been high for longer time, as none of the crew had visible burns after the incident or affections of eyes that can be related to the exposure event. It has been reported that RF pulses of high peak power might be auditory perceived as clicks or as a buzzing sound if the repetition rate of the pulse is high [18], but the extent of this phenomenon is not clear [20]. None of the crew members reported any such sounds during the incident.

At the examination in the hospital more than half a year after the incident, the crew was found to be a healthy group of persons, with no signs of skin affection, no cataract, no general health problems, no affection of the nervous system or any abnormal blood analyses. The crew had clearly less subjective health complaints than what we find in a normal population, and the symptoms had evidently disappeared. These findings are in line with previous studies and overviews of the 'over-exposure' episodes, showing that radar exposure only causes health problems when it has led to serious heating of the persons involved [8]. Some eye abnormalities were found among the crew members. These were not likely to be caused by the radar exposure, as most of them were found among the crew who were inside the ship nearly all of the exposure period. Also, eye abnormalities like myopia, hypermetropia and keratoconus have never been shown to be associated with RF EMF exposure [21]. However, the situation on board caused a relatively high focus upon possible adverse health effects of the eyes due to the radar exposure. This situation might have caused more rubbing of the eyes than normally among some of the crew, and this might have worsened or started a keratoconus [22].

Many of the personnel involved were worried about the possibility of long-term health effects. With the current knowledge of radar exposure and health, there is no reason to fear such effects from the radar exposure [9-12]. They did not seem to have been informed about this present knowledge. Their worries had probably been caused by the lack of information about the radar exposure, as they were thinking the exposure must have been extremely high since they were not properly informed, and since equipment on board the ship was affected.

The crew and the documents from the navy described periods with numerous symptoms among the personnel after the radar incident. The symptoms were from several organ systems, and developed days and weeks after the exposure. Similar problems have been described in previous studies of the 'over-exposure' to radar. Persons who suspect to have been exposed are shown to experience non-specific symptoms such as headache and fatigue after the incident, and the reasons for this are not entirely clear $[5,6]$. It has been suggested that the symptoms may arise as the persons involved are put in a special stress situation. A report from the U.S. Air Force from 1985 describes similar incidents among a total of 330 people suspected of being 'over-exposed'. They all described similar symptoms as seen in the present study, but it turned out that only 58 had actually been radar exposed [23, 24]. Such stress reaction following special events has been known for many years, and can also occur in other populations where one fears the health effects of specific exposures $[25,26]$. It may take time before these stress reactions or symptoms disappear completely. Such events are very scary and some time is needed to leave them behind. The symptoms can disappear quickly for some persons and last many months in others.

Could the symptom development among the crew have been avoided? We think that it is likely. Guidelines for this type of situations do exist and should have been used [8, 27]. These guidelines suggest that it is very important to intervene quickly among personnel who have been exposed. The exposure should be confirmed and the involved persons should be examined immediately after the event to confirm the presence or lack of effects from heating. The guidelines [27] emphasise the importance of quick actions, information and reassurance to reduce the anxiety among persons who have been exposed. Immediate actions after a possible radar exposure event can be summarised in the following way:

I. Address the exposure

Was any exposure actually present? Exposure assessment must be performed: Type of exposure, exposure level and exposure duration.

II. Health examination

a) If there are no signs of heating after an exposure incident, there will be no health problems. This must be stated clearly to the crew and they must also be informed about the knowledge of no risk regarding long-term health effects. However, it might also be important to inform the crew about the high risk of developing subjective health complaints after such an episode, and that this kind of reaction can be quite normal. Although such symptoms can be avoided by correct and clear information, exposed personnel will be at risk of anxiety and somatisation for a while after such incidents.

b) If overheating is present, general hyperthermia and burns must be treated and relevant follow-up examinations must be planned and performed. This treatment will depend upon clinical findings and on a symptomatic basis, preferably by an occupational physician.

In the present situation, several physicians examined the crew. However, it is not clear what kind of conclusions the physicians ended up with and what kind of information they gave the crew members. We have no detailed 
information on the topic. Nevertheless, it might have been possible that no clear information was given, as some of the physicians were young and inexperienced, and may have had minor knowledge about radar and health effects. Competence about electromagnetic fields and possible health effects is of major importance to give assuring information to persons who have experienced a possible 'over-exposure'. Advices of writing a symptom diary, like this crew did, seem for instance to be contradicted in such a situation, increasing the focus on symptoms rather than reducing them. Also, the naval secrecy about the radar exposure is very likely to have worsened the situation for the crew, creating rumours and worries.

At the time of examination at the hospital almost a half year after the event, the symptoms seemed to be fading away. This might be caused by the substantial time that had passed, but could also be the effect of the systematic hospital examination. The crew was informed that the physicians examining them had high qualifications in occupational health and ophthalmology, and that they had high knowledge about radar and health effects. This might have reassured the crew and reduced the anxiety among them.

In Norway, few of the health personnel have special knowledge about radar exposure. The main competence in this area is present at the Norwegian Radiation Protection Authority, and the number of health personnel here is low. We suggest the establishment of an advising unit for such events in Norway to help out when incidents like the one presented here occurs.

\section{CONCLUSIONS}

Part of the crew of the Norwegian naval ship was exposed to radar waves during an incident at sea. The personnel did not experience any major heating during the episode. They had no objective signs of adverse health effects afterwards and the long-term health effect from the exposure is highly unlikely. However, many of the crew developed a number of subjective health effects after the incident, probably due to the fear of possible health consequences. Better routines for such incidents at sea should be developed to avoid this type of anxiety.

\section{REFERENCES}

1. Mclaughlin JT. Tissue destruction and death from microwave radiation. California Medicine 1957; 86: 336-339.

2. Knauf CGM. Microwave exposure and missile propellants as occupational health problems. Occ Health Problems 1960; 50: 364-367.

3. Schilling $\mathrm{CJ}$. Effects of exposure to very high frequency radiofrequency radiation on six antenna engineers in two separate incidents. Occ Med 2000; 80: 49-56.

4. Schilling $\mathrm{CJ}$. Effects of acute exposure to ultrahigh radiofrequency radiation on three antenna engineers. Occ Environ Med 1997; 54: 281-284.

5. Electromagnetic fields and public health: radar and human health. WHO, fact sheet No 226 .

6. Pollack H. Medical aspects of exposure to radiofrequency radiation including microwaves. Southern Med J 1983; 76: 759-765.
7. Ryan KL, D'Andrea JA, Jauchem JR, Mason PA. Radio frequency radiation of millimeter wave length: Potential occupational safety issues relating to surface heating. Health Phys 2000; 78: 170-181.

8. IEEE Committee on man and radiation (COMAR). Medical aspects of radiofrequency radiation overexposure. Health Physics 2002; 82: 387-391.

9. Weak electromagnetic fields - an evaluation of health risk and practice (In Norwegian: Svake høyfrekvente elektromagnetiske felt - en vurdering av helserisiko og forvaltningspraksis). Report from an expert group in Norway. The Norwegian Institute of Public Health, Oslo, Norway, 2012.

10. Research on EMF and Health Risks. Seventh annual report from Strålsäkerhetsmyndighetens (SSMs) Independent Expert Group on Electromagnetic Fields. Stockholm, Sweden, 2010.

11. The Scientific Committee on Emerging and Newly Identified Health Risks (SCENIHR). Health Effects of Exposure to EMF. European Commission, 2010.

12. Possible health effects of occupational radar exposure (In Norwegian: Mulige helseeffekter av yrkesmessig strålingseksponering fra radar). Report from an expert group. The Norwegian Ministry of defense, Oslo, Norway, 2007.

13. Eriksen HR, Ihlebaek C, Ursin H. A scoring system for subjective health complaints (SHC). Scand J Publ Health 1999; 27: 63-72.

14. Inlebaek C, Eriksen $\mathrm{H}$, Ursin H. Prevalence of subjective health complaints (SHC) in Norway. Scand J Public Health 2002; 30: 20-29.

15. Folstein MF, Folstein SE, McHugh PR. "Mini-mental state”. A practical method for grading the cognitive state of patients for the clinician. J Psych Res 1975; 12: 189-198.

16. http://mostlymissiledefense.com/2012/08/03/ballistic-missile-defense-the-aegis-spy-1-radar-august-3-2012/ (accessed 2013-08-24).

17. Knott EF, Shaeffer JF, Tuley MT. Radar Cross Section. Chapter 2.4.1. Artech House, Boston 1993.

18. Moen BE, Wieslander G, Bakke JV, Norbäck D. Subjective health complaints and psychosocial work environment among university personnel. Occup Med 2013; 63: 38-44.

19. D'Andrea JA, Ziriax JM, Adair ER. Radio frequency electromagnetic fields: mild hyperthermia and safety standards. Prog Brain Res 2007; 162: 107-135.

20. International Commission on Non-lonizing Radiation Protection (ICNIRP) Guidelines for limiting exposure to time-varying electric, magnetic, and electromagnetic fields (up to $300 \mathrm{GHz}$ ). International Commission on Non-lonizing Radiation Protection. Health Physics 2009; 97: 257-259.

21. Elder JA. Ocular effects of radiofrequency energy. Bioelectromagnetics Suppl 2003; S148-S161.

22. McMonnies $\mathrm{CW}$. Abnormal rubbing and keratectasia. Eye Contact Lens 2007; 33: 265-271.

23. Eisenberg J, Sylvain D, Durgam S. Nonionizing radiation exposure to technicians at a satellite communication facility. National Institute of Occupational Safety and Health, June 2008.

24. Coughlin J. The medical results of human exposures to radio frequency radiation. Report 85-029CV111ARA. Unites States Air Force Occupational and Environmental Health Laboratory Aerospace Medical Division, Texas, 1985.

25. Göthe C-J, Molin C, Nilsson CG. The environmental somatization syndrome. Psychosomatics 1995; 36: 1-11.

26. Hahn RA. The nocebo phenomenon: Concept, evidence and implications for public health. Preventive Medicine 1997; 26: 607-611.

27. Radio frequency radiation: High Power Microwave Devices. Guidance for Doctors in the assessment and acute treatment of a patient suspected of over exposure to radio frequency radiation. US Army Public Health command. Fact sheet 2011: 24-010-1011 (http://phc. amedd.army.mil/Pages/Library.aspx. $24^{\text {th }}$ Aug 2013). 